that it is of paramount importance not to increase the scale of the present tests of nuclear weapons and that control of such tests with the object of eventual abolition should be our aim. Mr. Richard Foot stressed the importance of the further research work on the genetic effects of radiation and other matters which the Commitive recommends should continue, and Mr. A. Blenkinsop, asking whether research work in Britain is adequate, urged the importance of encouraging vigorously all the international research work proceeding in this field. The Minister of Health, $\mathrm{Mr}$. R. H. Tur'ton, replying in the debate, said that the Government regards the expansion of research as a matter of high priority in order that the potentialities of nuclear radiation may be exploited with confidence and safety; immediate action will be taken when the Committee submits to the Medical Research Council its recommendations for future work. The Atomic Energy Authority would have no difficulty in carrying out the recommendations of the report regarding occupational exposure to radiation. He reiterated the Governmen's's intention to do its best to secure progress in the regulation and limitation of test explosions, and mentioned that the Radioactive Substances Advisory Committee, under the chairmanship of Sir Charles Darwin, has prepared a comprehensive code of practice for use in the National Health Service hospitals. This is under final revision and will be issued shortly. To assist in carrying out the code, as well as in applying existing protective measures in hospitals and in industry, a Radiological Protection Service has been set up and, in accordance with the recommendation that present practice in diagnostic radiology should be reviewed and the use of radiotherapy in non-malignant condition critically examined, the Government is appointing a committee of scientists and professional men, with Lord Adrian as chairman, to examine these essentially clinical matters and make recommendations. Recommendations for collecting more detailed information for genetic studies would be discussed with the Registrar General.

\section{A Winge Festschrift}

A volume in honour of the seventieth birthday of the distinguished Danish botanist, Prof. Öjvind Winge, of the Carlsberg Laboratory, Copenhagen, has recently appeared (as Vol. 26 of the Comptes Rendus des Travaux du Laboratoire Carlsberg, Sér. Physiologique ; pp. $1-443$; $1956 ; 40 \mathrm{kr}.) . \quad$ As is appropiriate and to be expected, it is concerned almost entirely with the genetics of micro-organisms. It includes a bibliography of Prof. Winge's own scientific publications, these amounting to 120 titles, extending from the year 1907 to date, the whole constituting a notable contribution to a subject of great contemporary interest and increasing importance. The individual papers in the volume have been contributed by eminent exponents in the field. of the genetics and physiological genetics of microorganisms. Some of these relate to specific topics and observations; for example, gigas mutants; others pertain to what is now referred to as the biochemistry of genetics, for example, "The Genetics of Galactose Fermentation in Saccharomyces Hybrids" ; and yet others deal with more general topics, such as "Genes-their Nature and Function". Altogether, there are twenty-five separate contributions, the overall effect being to provide the reader not only with a representative survey but also to give him a very lively impression of the effort that is being made in different parts of the world in a difficult but rewarding field. Like other publications from the Carlsberg Laboratory, the volume is attractively produced.

\section{Journal of Fluid Mechanics}

THE recent increase in the number of investigations, both theoretical and experimental, relating to the study of fluid mechanics has necessitated the launching of a new periodical devoted solely to this subject, the Journal of Fluid Mechanics. The Journal is to be issued in six parts to a volume of approximately six hundred pages, and the first number has recently been published (London: Taylor and Francis, Ltd.; New York: Academic Press, Inc. $20 s$. or 3 dollars per part; $£ 510 s$. or 16.50 dollars per vol.). The editor is Dr. G. K. Batchelor (Cavendish Laboratory, Cambridge), assisted by Drs. T. B. Benjamin and I. Proudman; and Profs. G. F. Carrier (Harvard), W. C. Griffith (Princeton) and M. J. Lighthill (Manchester) are associate editors. The first issue contains eight papers, all of which are of high standard: four relate to aerodynamics, one to oceanography, one to rainfall, and the remaining two, by M. I. Lighthill and M. B. Glauert, respectively, of the Department of Mathematics, University of Manchester, deal with the theoretical discussion of drift and boundary-layer flow on oscillating plates and cylinders, respectively. M. D. Van Dyke (Ames Aeronautical Laboratory, California) obtains a second approximation to the solution of the problem of supersonic flow past unyawed elliptic cones by proceeding from the slender-body theory; L. C. Woods (Sydney) discusses the thrust due to an air-jet flowing from a wing placed in a wind tunnel and establishes that the ideal thrust is almost independent of the jet exit angle; V. Blackman (Princeton) describes a study of vibrational relaxation in oxygen and nitrogen in the range of shock waves of Mach-number speeds 3-10 ; and N. Rott (Cornell) investigates theoretically the diffraction of weak shock waves near the edge of a sharp wedge. A theory of collisions between small drops in a turbulent fluid, taking into account collisions between equal drops, is given by $\mathrm{P}$. G. Saffman and J. S. Turner (Trinity College, Cambridge), and the results are applied to the case of small drops in atmospheric clouds to test the importance of turbulence in initiating rainfall. Finally, J. Grease (National Institute of Oceanography, Dorking) considers the problem, arising in connexion with the propagation of tides and storm surges in the ocean, of long gravity waves on a rotating Earth approaching a semi-infinite barrier parallel to the wave crests.

\section{Health Education in Factories}

THE health committee of the County Borough of Willesden (London) has been considering means of interesting people in health education (Health Educ. $J ., 14 ; 1956)$. During the past seven years, health talks on a variety of subjects have been given to religious, social and political organizations, trade unions, and many clubs. The audiences have varied from about twenty to eighty; but there has recently been a tendency for them to decline. Some talks had already been given in factories by special requests from the managements, and it was thought that here appreciative audiences might be found. At the end of 1954 it was decided to explore the possibility 